\title{
Screening for human milk amino acids by HPLC-ESI-MS/MS in the study of the immunonutrition of the newborn infants
}

\author{
C. L. Sánchez ${ }^{1}$, A. F. Toribio ${ }^{2}$, J. Cubero ${ }^{1}$, J. Sánchez ${ }^{3}$, J. Maynar², A. B. Rodríguez ${ }^{1}$, M. Rivero ${ }^{4}$ \\ and C. Barriga ${ }^{1}$ \\ ${ }^{1}$ Department of Physiology, Faculty of Science, University of Extremadura, Badajoz, Spain, ${ }^{2}$ Department of Analytical \\ Chemistry, Faculty of Science, University of Extremadura, Badajoz, Spain, ${ }^{3}$ Laboratory of Metabolism, Hospital 'Perpetuo \\ Socorro', Servicio Extremeño de Salud (SES), Badajoz, Spain and ${ }^{4}$ Scientific Division, Ordesa Group, Barcelona, Spain
}

The effect of amino acids on the nutrition of a newborn is a determining factor in this first stage of life, and their correct level in breast milk is vital. Among the nutrients with a suggested positive effect on immune functions, there are some amino acids such as tryptophan, arginine, glutamine, taurine and others ${ }^{(1-3)}$. Our purpose was to develop a new method for the assay of amino acids in human milk by HPLC-ESI-MS/MS after acid hydrolysis. We collected the breast milk samples from 31 healthy mothers living throughout Community of Extremadura (Spain) from January 2008 to December 2008 with less than two months of lactation, and stored at $-80^{\circ} \mathrm{C}$. Their median age was 33 years (minimum-to-maximum range, 26-39 years), and the means \pm SD values for weight, height and body mass index (BMI) were $62.3 \pm 7.3 \mathrm{~kg}, 164 \pm 6 \mathrm{~cm}$ and $23.1 \pm 2.4 \mathrm{~kg} / \mathrm{m}^{2}$, respectively. The subjects were considered healthy on the basis of their breastfeeding success, a physical examination, and a follow-up. All subjects were informed about the investigation, and gave their written consent. The duplicated samples were dissociated by acidic hydrolysis ( $\mathrm{HCl} 6 \mathrm{~N}$ ) and analysed by a Waters 2795 Alliance HT HPLC (Milan, Italy) was coupled to a Micromass Quattro Ultima mass spectrometer (Milan, Italy) with an ESI (Electrospray Ionisation) source, together with an Agilent Zorbax Eclipse AAA C18 column $(3.0 \mathrm{~mm} \times 150 \mathrm{~mm} \times 3.5 \mu \mathrm{m})$ for amino acid analysis. The liquid chromatography-tandem mass conditions were: the column temperature was set at $80^{\circ} \mathrm{C}$; source temperature was $80^{\circ} \mathrm{C}$; desolvation gas flow 650 litres/h; cone gas and voltage was 0 litre/h and $55 \mathrm{~V}$, respectively; capillary voltage $3.50 \mathrm{kV}$. The physiologically and immunonutritionally important human milk amino acids were detected at concentrations of (means $\pm \mathrm{SE}$ ):

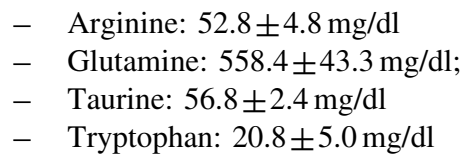

Amino acids are significant nutrients in infant growth and their positive effects on immune system have been studied extensively, and HPLC-ESI-MS/MS is a sensitive and efficient tool for the assay of these analites in breast milk. Under the conditions used, chromatographic separation took $10 \mathrm{~min}$ with a re-equilibration time of $5 \mathrm{~min}$ in order to restore retention. This method could be used for the qualitative analysis of 40 underivatised amino acids and for the quantification of 20 of them. These data will serve to perfect commercial infant formula milks, and bring them closer to the reference standard represented by human milk.

1. Levy J (1998) Nutrition 14, 641-647.

2. Cubero J, Narciso D, Terrón P et al. (2007) Neuroendocrinol. Lett 28, 360-366.

3. Gunerhan Y, Koksal N, Sahin UY et al. (2009) World J Gastroenterol 15, 467-472. 